\title{
Plasmaspheric depletion, refilling, and plasmapause dynamics: A coordinated ground-based and IMAGE satellite study
}

\author{
Z. C. Dent, ${ }^{1}$ I. R. Mann, ${ }^{1}$ J. Goldstein, ${ }^{2}$ F. W. Menk, ${ }^{3}$ and L. G. Ozeke ${ }^{1}$
}

Received 3 February 2005; revised 24 October 2005; accepted 29 November 2005; published 3 March 2006.

[1] This paper presents a coordinated ground-based magnetometer and IMAGE satellite study of plasma mass density and plasmapause location on L shells between 2.39 and 6.54 throughout an extended interval of moderate geomagnetic activity from 5 to 17 May 2001. Storm-time plasmaspheric depletion is monitored using three different data sets, and our results show the importance of local time history effects on plasma depletion, including determining that shorter intervals of enhanced convection do not necessarily cause all meridian sectors to be depleted. Analysis of ground-based magnetometer derived mass density implies that poststorm refilling is not a steady process through the dayside sector. Our results also suggest that refilling may be a two-stage process, operating with a much increased rate on the third day of clear refilling. Comparisons between timedependent ground-based magnetometer cross-phase and IMAGE RPI determined plasma mass density profile evolution imply the presence of an enhanced heavy ion population in the inner plasmatrough during an active refilling interval. These results further demonstrate the potential of using ground-based magnetometer data to study cold plasma dynamics.

Citation: Dent, Z. C., I. R. Mann, J. Goldstein, F. W. Menk, and L. G. Ozeke (2006), Plasmaspheric depletion, refilling, and plasmapause dynamics: A coordinated ground-based and IMAGE satellite study, J. Geophys. Res., 111, A03205, doi:10.1029/2005JA011046.

\section{Introduction}

[2] The cold dense inner region of the magnetosphere, the plasmasphere, is known to be highly dynamic. Its outer regions can be stripped away during geomagnetic storms to form plumes which convect through the dayside magnetosphere toward the magnetopause, where the plasma is believed to be lost. Alternatively, flux tubes may be depleted by direct loss of plasma from the inner plasmasphere to the ionosphere [e.g., Lemaire et al., 1998]. With decreasing geomagnetic activity, depleted flux tubes are subsequently replenished from the underlying ionosphere, i.e., they refill. While this pattern of activity is well documented [e.g., Chappell et al., 1971; Carpenter and Park, 1973; Carpenter and Anderson, 1992; Menk et al., 1999], the physics of these processes, especially refilling, is not fully understood. As yet we do not have a basic understanding of the time taken for flux tubes to become depleted and subsequently to replenish, for example as a function of activity level, Lshell, or the local time of the flux tube at storm onset. The time at which refilling commences can also be difficult to determine and so hinders thorough examination of the time dependence of these processes.

\footnotetext{
${ }^{1}$ Department of Physics, University of Alberta, Edmonton, Alberta, Canada.

${ }^{2}$ Space Science and Engineering Division, Southwest Research Institute, San Antonio, Texas, USA.

${ }^{3}$ School of Mathematical and Physical Sciences and CRC for Satellite Systems, University of Newcastle, Callaghan, New South Wales, Australia.

Copyright 2006 by the American Geophysical Union. 0148-0227/06/2005JA011046\$09.00
}

[3] The primary cold ion population of the inner magnetosphere is $\mathrm{H}^{+}$, with $\mathrm{He}^{+}$usually being the secondary population. Observed $\mathrm{He}^{+} / \mathrm{H}^{+}$number density ratios vary from 0.01 to 0.5 [e.g., Taylor et al., 1965; Horwitz et al., 1984; Craven et al., 1997; Goldstein et al., 2003]. $\mathrm{O}^{+}$is usually the third most dominant ion in the cold plasma population, although its number density can at times be comparable to that of $\mathrm{H}^{+}$[Horwitz et al., 1984]. The $\mathrm{O}^{+}$ number density is typically $1-6 \mathrm{~cm}^{-3}$ in the plasmasphere, and while the admixture of these ion populations is often assumed to be stable with time and location, satellite observations have shown an enhancement of the $\mathrm{O}^{+}$population in the vicinity of the plasmapause following plasma depletion episodes [e.g., Horwitz et al., 1984; Fraser et al., 2005].

[4] In this paper we present ground-based magnetometer and IMAGE satellite Extreme UltraViolet (EUV) Imager and Radio Plasma Imager (RPI) results obtained throughout a prolonged interval of moderate activity, 5-17 May 2001, during which two geomagnetic storm associated depletion and subsequent refilling episodes occurred. In addition, the plasmapause location determined using two empirical models is presented and compared to the observational results. Plasma depletion, refilling, and plasmapause dynamics are studied, in addition to the heavy ion dynamics which took place throughout the chosen interval.

\section{Instrumentation}

[5] The cold plasma population of the magnetosphere may be monitored using a number of instruments and 
Table 1. Ground-Based Magnetometer Station Pairs Employed

\begin{tabular}{|c|c|c|c|c|c|c|}
\hline Station Pair & L-shell of Midpoint & Lower L-value & Upper L-value & $\Delta \mathrm{L}$ & LT & MLT (CGM) \\
\hline HAD-YOR & 2.39 & 2.25 & 2.56 & 0.31 & $\mathrm{UT}-0$ hours $11 \mathrm{~min}$ & $\mathrm{UT}+0$ hours $43 \mathrm{~min}$ \\
\hline YOR-ESK & 2.67 & 2.56 & 2.78 & 0.22 & $\mathrm{UT}-0$ hours $14 \mathrm{~min}$ & $\mathrm{UT}+0$ hours $49 \mathrm{~min}$ \\
\hline YOR-GML & 2.80 & 2.56 & 3.08 & 0.52 & $\mathrm{UT}-0$ hours $09 \mathrm{~min}$ & $\mathrm{UT}+0$ hours $49 \mathrm{~min}$ \\
\hline ESK-GML & 2.92 & 2.78 & 3.08 & 0.30 & UT -0 hours $14 \mathrm{~min}$ & $\mathrm{UT}+0$ hours $46 \mathrm{~min}$ \\
\hline ESK-LER & 3.16 & 2.78 & 3.63 & 0.85 & $\mathrm{UT}-0$ hours $09 \mathrm{~min}$ & $\mathrm{UT}+0$ hours $53 \mathrm{~min}$ \\
\hline GML-LER & 3.34 & 3.08 & 3.63 & 0.55 & $\mathrm{UT}-0$ hours $10 \mathrm{~min}$ & $\mathrm{UT}+0$ hours $54 \mathrm{~min}$ \\
\hline NUR-HAN & 3.58 & 3.41 & 3.78 & 0.37 & $\mathrm{UT}+1$ hours $43 \mathrm{~min}$ & $\mathrm{UT}+2$ hours $41 \mathrm{~min}$ \\
\hline GML-FAR & 3.60 & 3.08 & 4.26 & 1.18 & UT -0 hours $21 \mathrm{~min}$ & $\mathrm{UT}+0$ hours $44 \mathrm{~min}$ \\
\hline KVI-NOR & 3.79 & 3.27 & 4.47 & 1.20 & $\mathrm{UT}+1$ hours $02 \mathrm{~min}$ & $\mathrm{UT}+2$ hours $07 \mathrm{~min}$ \\
\hline NUR-OUL & 3.90 & 3.41 & 4.51 & 1.10 & $\mathrm{UT}+1$ hours $41 \mathrm{~min}$ & $\mathrm{UT}+2$ hours $42 \mathrm{~min}$ \\
\hline LER-FAR & 3.92 & 3.63 & 4.26 & 0.63 & $\mathrm{UT}-0$ hours $16 \mathrm{~min}$ & $\mathrm{UT}+0$ hours $52 \mathrm{~min}$ \\
\hline HAN-OUL & 4.12 & 3.78 & 4.51 & 0.73 & $\mathrm{UT}+1$ hours $45 \mathrm{~min}$ & $\mathrm{UT}+2$ hours $47 \mathrm{~min}$ \\
\hline OUJ-SOD & 4.76 & 4.33 & 5.27 & 0.94 & $\mathrm{UT}+1$ hours $48 \mathrm{~min}$ & $\mathrm{UT}+2$ hours $54 \mathrm{~min}$ \\
\hline LYC-KIR & 4.97 & 4.45 & 5.57 & 1.12 & $\mathrm{UT}+1$ hours $18 \mathrm{~min}$ & $\mathrm{UT}+2$ hours $30 \mathrm{~min}$ \\
\hline OUL-KIL & 5.20 & 4.51 & 6.10 & 1.59 & $\mathrm{UT}+1$ hours $33 \mathrm{~min}$ & $\mathrm{UT}+2$ hours $45 \mathrm{~min}$ \\
\hline PEL-MUO & 5.35 & 5.13 & 5.58 & 0.45 & $\mathrm{UT}+1$ hours $35 \mathrm{~min}$ & $\mathrm{UT}+2$ hours $47 \mathrm{~min}$ \\
\hline SOD-IVA & 5.49 & 5.26 & 5.74 & 0.48 & $\mathrm{UT}+1$ hours $48 \mathrm{~min}$ & $\mathrm{UT}+2$ hours $59 \mathrm{~min}$ \\
\hline KIR-KIL & 5.82 & 5.58 & 6.10 & 0.52 & $\mathrm{UT}+1$ hours $22 \mathrm{~min}$ & $\mathrm{UT}+2$ hours $40 \mathrm{~min}$ \\
\hline MUO-MAS & 5.89 & 5.58 & 6.24 & 0.66 & $\mathrm{UT}+1$ hours $34 \mathrm{~min}$ & $\mathrm{UT}+2$ hours $50 \mathrm{~min}$ \\
\hline ABK-TRO & 6.15 & 5.83 & 6.48 & 0.65 & $\mathrm{UT}+1$ hours $16 \mathrm{~min}$ & $\mathrm{UT}+2$ hours $36 \mathrm{~min}$ \\
\hline MAS-SOR & 6.45 & 6.24 & 6.86 & 0.62 & $\mathrm{UT}+1$ hours $32 \mathrm{~min}$ & $\mathrm{UT}+2$ hours $42 \mathrm{~min}$ \\
\hline KIL-SOR & 6.46 & 6.10 & 6.86 & 0.76 & $\mathrm{UT}+1$ hours $26 \mathrm{~min}$ & $\mathrm{UT}+2$ hours $47 \mathrm{~min}$ \\
\hline
\end{tabular}

techniques. We will present data from ground-based magnetometers in the European sector and the IMAGE satellite RPI and EUV instruments.

[6] The cross-phase technique has been developed in order to allow a latitudinal (or L-dependent) profile of field line resonance frequencies to be determined using arrays of latitudinally separated ground-based magnetometers [e.g., Waters et al., 1991; Baransky et al., 1989]. The technique assumes that each field line is excited at its natural frequency, although the power at this frequency need not dominate the spectra. By comparing the amplitude and phase spectra from two latitudinally separated ground-based magnetometer stations, the local field line resonance frequency may be identified. [Menk et al., 1999] first discussed the use of ULF field line resonances for examining temporal variations of plasmaspheric density, including poststorm refilling.

[7] The natural field line resonance frequency of a flux tube is dependent upon the length of that tube, and the magnetic field strength, plasma mass density, and their distributions along the flux tube. By assuming some geomagnetic field geometry and plasma density distribution, an observed latitudinal profile of resonance frequencies may be inverted in order to determine a plasma mass density profile in the equatorial plane. In order to achieve this for this study, the toroidal mode wave equation for a dipolar geometry set out by Radoski [1967] has been solved numerically, assuming a radial density distribution along a field line $\propto \mathrm{r}^{-\alpha}$, with $\alpha=0$. In the plasmasphere a radial density variation with $\alpha=1$ or 0 is expected to be a reasonable approximation [e.g., Goldstein et al., 2001; Denton et al., 2004], whereas in the plasmatrough perhaps a radial variation with $\alpha=3$ or 4 would be more appropriate [e.g., Angerami and Carpenter, 1966; Menk et al., 1999]. The difference in inferred density due to the choice of $\alpha$ between 0 and 4 is $\sim 20 \%$, as determined for a field line resonance frequency of $10 \mathrm{mHz}$ at $\mathrm{L}=4.12$. This variation is typically less than that due to the uncertainty associated with determining the resonance frequencies for this study, and hence we have chosen to use a value of $\alpha=0$ for all Lshells, for the sake of consistency. Note that the value of $\alpha$ may vary throughout plasma depletion and refilling intervals [e.g., Reinisch et al., 2001], or diurnally [e.g., Menk et al., 1999], although since its variation is poorly understood we have chosen to use a single value throughout. The treatment given by Ozeke and Mann [2005] for the ionospheric boundary conditions for L-shells $\mathrm{L} \leq 4.0$ where the dipole magnetic field, $\mathbf{B}_{\mathbf{0}}$, cannot be assumed to be perpendicular to the ionosphere has also been included. A thorough review of this cross-phase technique is given, for example, by Menk et al. [2004].

[8] Note that the cross-phase method for determining a plasma mass density from a resonance frequency value makes the assumption of oscillation in the purely toroidal mode. In reality, however, poloidal and toroidal modes will in general be coupled. Orr and Matthew [1971] estimated that fundamental mode toroidal and guided poloidal frequencies differ by about 30\% and Menk et al. [1999] note that the actual density should fall somewhere between those calculated for a purely toroidal and purely guided poloidal mode. Any possible errors resulting from the decoupled toroidal mode assumption, or uncertainty associated with the choice of the value of $\alpha$, have not been included in the error bars presented later in this paper.

[9] The ground-based magnetometer data presented in this paper are from three arrays in the European sector: SAMNET (Sub-Auroral Magnetometer Network (http:// www.dcs.lancs.ac.uk/iono/samnet/)) [e.g., Yeoman et al., 1990], IMAGE (International Monitor for Auroral Geomagnetic Effects (http://www.ava.fmi.fi/image/)) [e.g., Lühr et al., 1998], and BGS (British Geological Survey, data available from SAMNET). The station pairs employed for the cross-phase analysis presented in this paper are given in Table 1. Errors associated with cross-phase determined densities are calculated from the range of uncertainty associated with determining the field line resonance frequencies. 

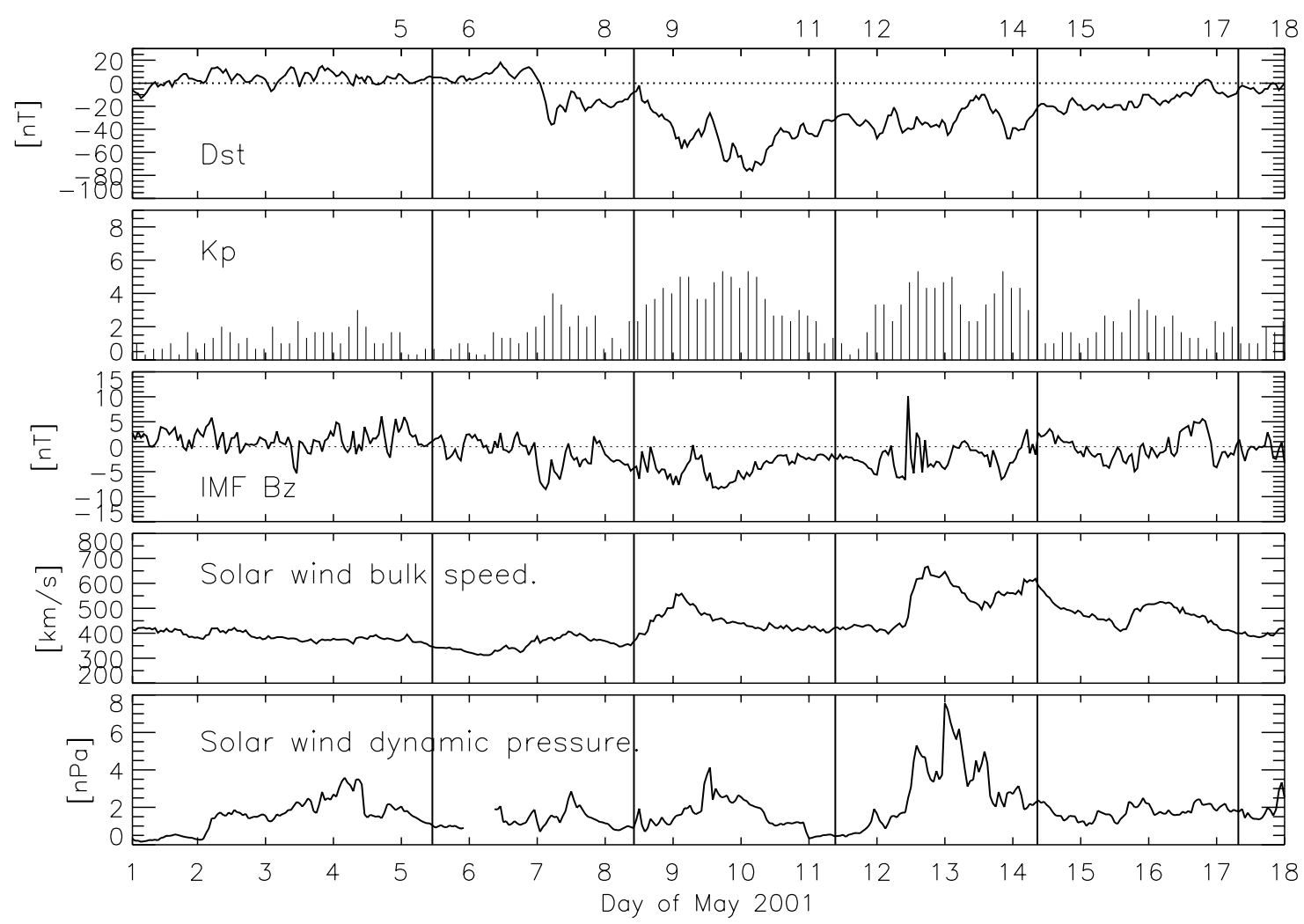

Figure 1. Kp, Dst, and ACE solar wind parameters as function of UT for 1-17 May 2001. A 1-hour time delay has been added to the solar wind data.

[10] The RPI instrument on board the elliptically orbiting IMAGE satellite passively measures the ambient electric field in order to determine the local plasma frequency and thus the in situ electron number density [e.g., Reinisch et al., 2000; Goldstein et al., 2003]. If the local plasma frequency cannot be identified, then the upper hybrid frequency is used in association with a magnetic field model in order to determine the local plasma frequency.

[11] In situ measurements of RPI determined densities are presented in this paper, i.e., no attempt has been made to map the in situ values to the equatorial plane. Goldstein et $a l$. [2001] note that the plasma density variation across field lines is often greater than along them. They studied Polar plasma wave data between $\mathrm{L}=2.3$ and 6.3 and for geocentric distance $r \geq 2 R_{E}$ in order to determine in situ electron number densities and found that density varied along field lines as $\mathrm{r}^{0.37 \pm 0.8}$ in the plasmasphere and as $\mathrm{r}^{-1.7 \pm 1.1}$ in the plasmatrough. Gallagher et al. [2000] studied data from the RIMS instrument on board the DE1 satellite and found little systematic variation of plasma density with latitude along field lines, within $\sim 40^{\circ}$ of the magnetic equator. More recently, Goldstein et al. [2003] determined that by assuming a constant density along a field line, within $20^{\circ}$ of the geomagnetic equator in the plasmasphere and $40^{\circ}$ in the plasmatrough, caused a maximum overestimation of equatorial electron number density values of $\leq 10 \%$ in the plasmasphere and $\leq 30 \%$ in the plasmatrough. The IMAGE RPI data presented in this paper were collected from magnetic latitudes between $46^{\circ} \mathrm{N}$ to $18^{\circ} \mathrm{S}$, and L-shells between 1.90 and 9.65. Thus it is appropriate to treat the in situ electron number densities determined via the IMAGE RPI instrument as a proxy for the equatorial electron number density. The maximum error associated with experimentally determining the in situ electron number density is believed to arise due to errors in determining the electron plasma frequency from emission spectra, and this error is assumed to be $12 \%$.

[12] The EUV Imager on board the IMAGE satellite currently provides the best single-instrument view of the global plasmasphere [e.g., Sandel et al., 2000]. It detects $30.4 \mathrm{~nm}$ ultraviolet light which has been resonantly scattered by the $\mathrm{He}^{+}$population of the plasmasphere. The images produced have spatial and temporal resolutions of $\sim 0.1 \mathrm{R}_{\mathrm{E}}$ and $\sim 10 \mathrm{~min}$, respectively, in two-dimensional (2-D) line-of-sight integrated pictures [e.g., Goldstein et al., 2003, 2004].

[13] The plasmapause location values presented in this paper have been determined via visual inspection of EUV images which have been mapped to the equatorial plane (as described for a single point by Goldstein et al. [2003]). Goldstein et al. [2003] note that the uncertainty associated with these values is dependent upon the sharpness of the plasmapause and is about $0.2 \mathrm{R}_{\mathrm{E}}$ for a sharp $\mathrm{He}^{+}$edge, and $0.4-0.8 \mathrm{R}_{\mathrm{E}}$ for diffuse structures.

[14] Goldstein et al. [2003] compared the plasmapause location as identified via RPI and EUV analysis throughout one month and found a very good correlation between the two techniques. Dent et al. [2003] compared ground-based magnetometer cross-phase and RPI determined plasma mass densities for a 1-day case study, and while there was excellent agreement in the inner plasmasphere, differences in the outer plasmasphere were identified by EUV 


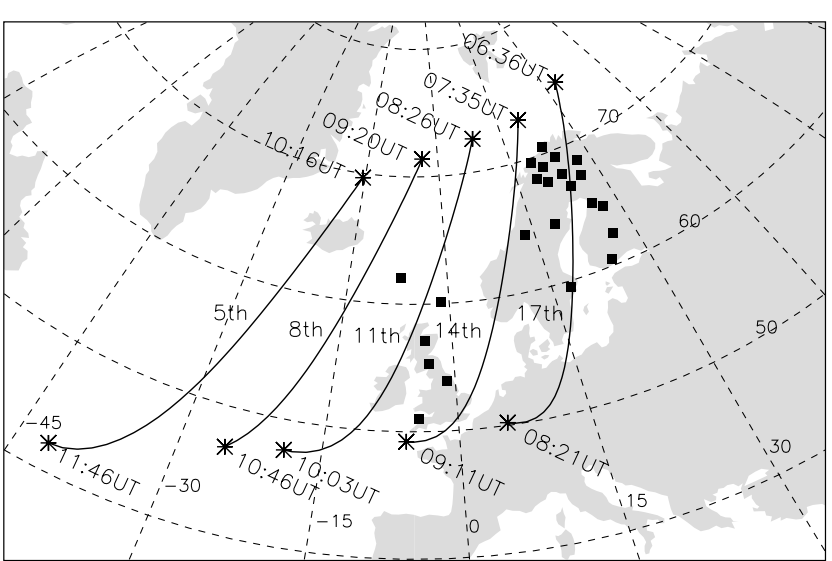

Figure 2. Map showing locations of the ground-based magnetometers used for this study (squares), and the Northern Hemisphere ground magnetic footprint of the IMAGE satellite inbound orbit during the intervals when RPI data was used for this study. Geographic coordinate grid lines and the time intervals of the IMAGE RPI data sets are shown. During these intervals the IMAGE satellite passed through magnetic latitudes from $45.71^{\circ} \mathrm{N}$ to $17.81^{\circ} \mathrm{S}$. Satellite data was obtained from SSCWeb, http://sscweb.gsfc.nasa.gov, assuming Tsyganenko 89 external and IGRF internal geomagnetic fields.

analysis to be due to azimuthally asymmetric plasma structure. Therefore the combined use of the RPI, EUV and ground-based magnetometer cross-phase techniques for this study should provide a valuable insight into the dynamics of plasmapause motion, and flux tube depletion and refilling which took place throughout the study interval.

\section{Observations}

[15] The data to be presented are from 5 to 17 May 2001, an extended interval of moderate geomagnetic activity during which two plasma depletion episodes took place. This event was chosen because every three days the IMAGE satellite had an excellent ground magnetic field line conjunction with the European magnetometer arrays used, enabling the long timescale of plasmaspheric morphology to be studied, including five ground-satellite "conjunction" days.

[16] Figure 1 shows a stack plot of the Dst and $\mathrm{Kp}$ geomagnetic indices, the IMF $\mathrm{B}_{\mathrm{Z}}$ (GSM coordinates), and the solar wind bulk speed and dynamic pressure. The solar wind parameters were measured by the MAG (magnetometer) and SWEPAM (Solar Wind Proton Alpha Monitor) instruments on board the ACE satellite (http:// www.srl.caltech.edu/ACE). From the location of the ACE satellite $\sim 1.45 \times 10^{6} \mathrm{~km}$ upstream, and at a bulk speed of $\sim 400 \mathrm{~km} \mathrm{~s}^{-1}$, the solar wind takes approximately 1 hour to travel to a nominal magnetopause at $10 \mathrm{R}_{\mathrm{E}}$, thus the solar wind data have been delayed by 1 hour. The vertical lines indicate the times of the ground-based and IMAGE (RPI) conjunctions to be presented later, and which are shown in Figure 2.

[17] Early on 7 May an increase in the level of geomagnetic activity was associated with a southward turning of the
IMF and slight increases of the solar wind bulk speed and dynamic pressure. The minimum value of Dst occurred early on 10 May, marking the end of the storm main phase. This interval relates to the first depletion episode to be examined below. A second depletion episode followed from the enhanced level of geomagnetic activity occurring from early on 12 May until 13 May. Note that the IMF was directed southward for much of the interval between 7 and 17 May 2001, and the Dst index showed depressed values for a much longer interval than for most geomagnetic storms.

[18] Two studies have been carried out for this interval. First, a long timescale study was undertaken of cross-phase determined field-line resonance frequency and corresponding plasma mass density profiles, IMAGE EUV determined plasmapause locations and empirically modeled plasmapause positions, and daily morning sector IMAGE RPI determined electron number density profiles. This study aims to examine the storm-time cold plasma dynamics and to gain some further understanding of the cold plasma depletion and refilling processes taking place, and how they are dependent on the time history of the local meridian being monitored. Second, a conjunction study compared cross-phase determined plasma mass density and IMAGE RPI determined electron number density profiles for the 5 days where the ground magnetic footprint of the IMAGE satellite had an excellent conjunction with ground-based magnetometers in the European sector. This second study also aims to examine the dynamics of any heavy ion population which may be present during the course of this geomagnetic storm.

\subsection{Long Timescale Study}

[19] Figures 3 and 4 show stacked plots of daily field line resonance frequency (eigenfrequency) profiles and the corresponding plasma mass density profiles (shown as semilog plots), respectively. These have been determined via the cross-phase technique for the 0900-1000 UT interval each day, using data windows of between 20 and $50 \mathrm{~min}$ duration. The previous day's profile is repeated in the following panel for ease of comparison of day to day variations. Error bars show the uncertainty associated with determining the observed frequency value, and the range of densities calculated using this range of frequency values. The arrows shown at the bottom of each panel in Figures 3 and 4 show the EUV determined plasmapause location; the grey arrow represents the first day in each panel, and the black panel the second day. These arrows show the median of the range of values of EUV determined plasmapause location determined for the magnetic longitude region covered by the ground-based magnetometers $\left(74.87^{\circ}-\right.$ $108.81^{\circ}$ ) and for the 0900-1000 UT interval where available. On the days when EUV data is not available for the 0900-1000 UT interval the median of the range of values determined for the same magnetic longitude sector and for the closest UT interval available before or after the 09001000 UT interval is shown. Goldstein et al. [2003] note that this process should be carried out in order to minimize any effects of erosion or refilling in the intervening time. The average range of values for EUV plasmapause location determined from a single EUV image for the longitude region of interest is $0.90 R_{E}$. 


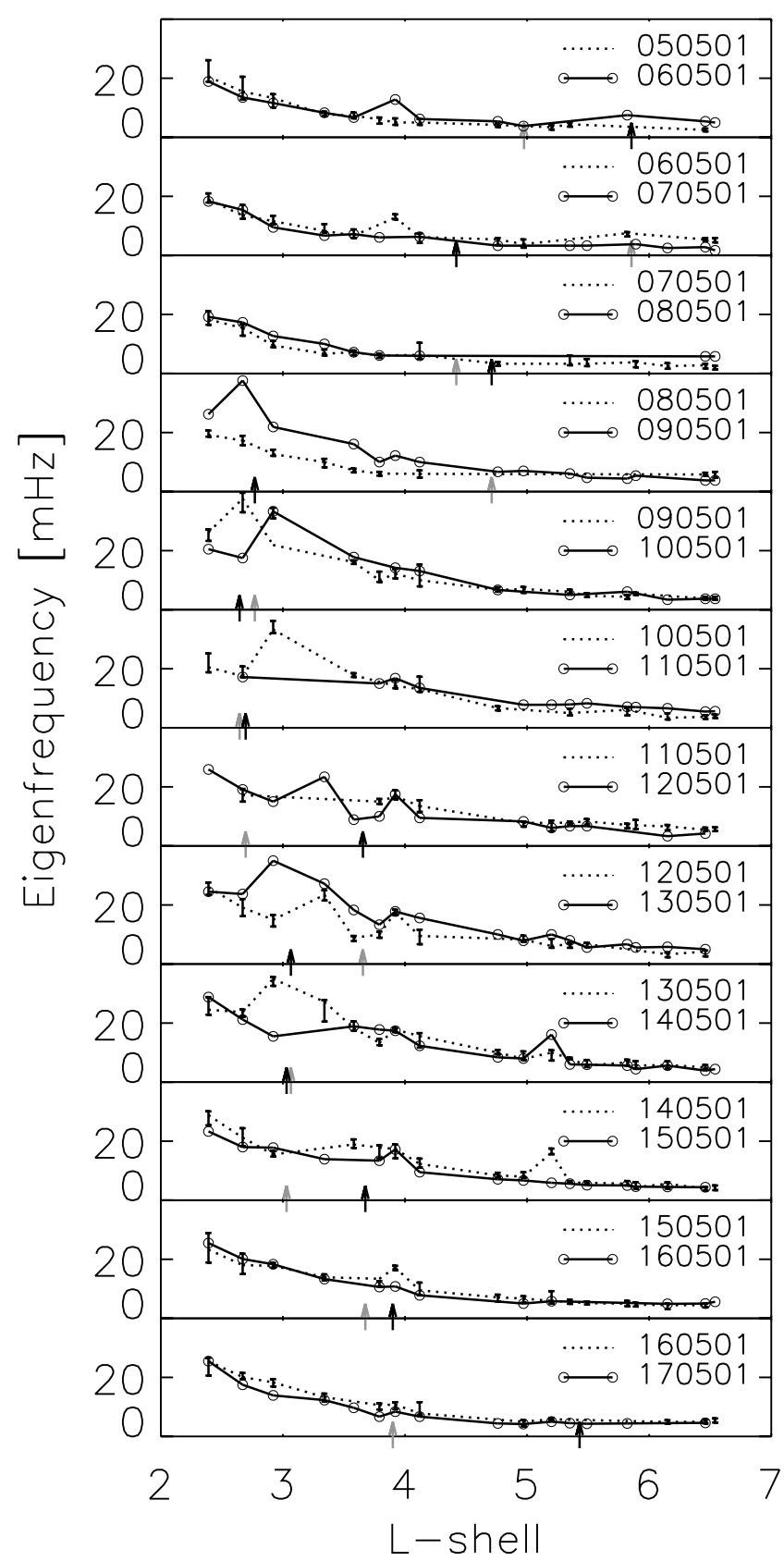

Figure 3. Stack plot showing cross-phase determined daily field line resonance frequency profiles for 5-17 May 2001 , determined for the $0900-1000$ UT interval. Note that lines are drawn connecting data points only to guide the eye. See text for details.

[20] In response to the first interval of enhanced geomagnetic activity on 7 May, significant plasmaspheric erosion occurred at $\mathrm{L}<4.12$ between 8 and 9 May (Figure 4). The EUV determined plasmapause locations in this plot show it moving inward from $\mathrm{L}>4.7$ to $\mathrm{L}<3.0$ in the same interval, and the eigenfrequency profile shows a positive gradient between $\mathrm{L}=2.39$ and $\mathrm{L}=2.67$ on 9 May (Figure 3), which is indicative of the plasmapause [e.g., Orr and Hanson, 1981]. Inside the EUV determined plasmapause, the density also decreases. Such loss is common and the plasma is understood to be lost to the underlying ionosphere [e.g.,
Bezrukikh et al., 2001; Carpenter and Lemaire, 1997]. Note that in the plasmatrough $(\mathrm{L}>4.5)$ the density varied by approximately an order of magnitude between 5 and 8 May in this local time sector but showed little variability between 8 and 10 May. This is consistent with the observation made by Goldstein et al. [2003] of more structure in the plasmatrough during quiet intervals as compared with active intervals.

[21] Between 9 and 10 May the positive gradient along the eigenfrequency profile moved outward by a fraction of an L-shell but otherwise showed little change until 12 May, implying almost no cold plasma loss or refilling took place through this interval. Note that on 11 May there is a lack of data points between $\mathrm{L}=2.67$ and 3.90 due to a suppression of the cross-phase peak. This is indicative of the station

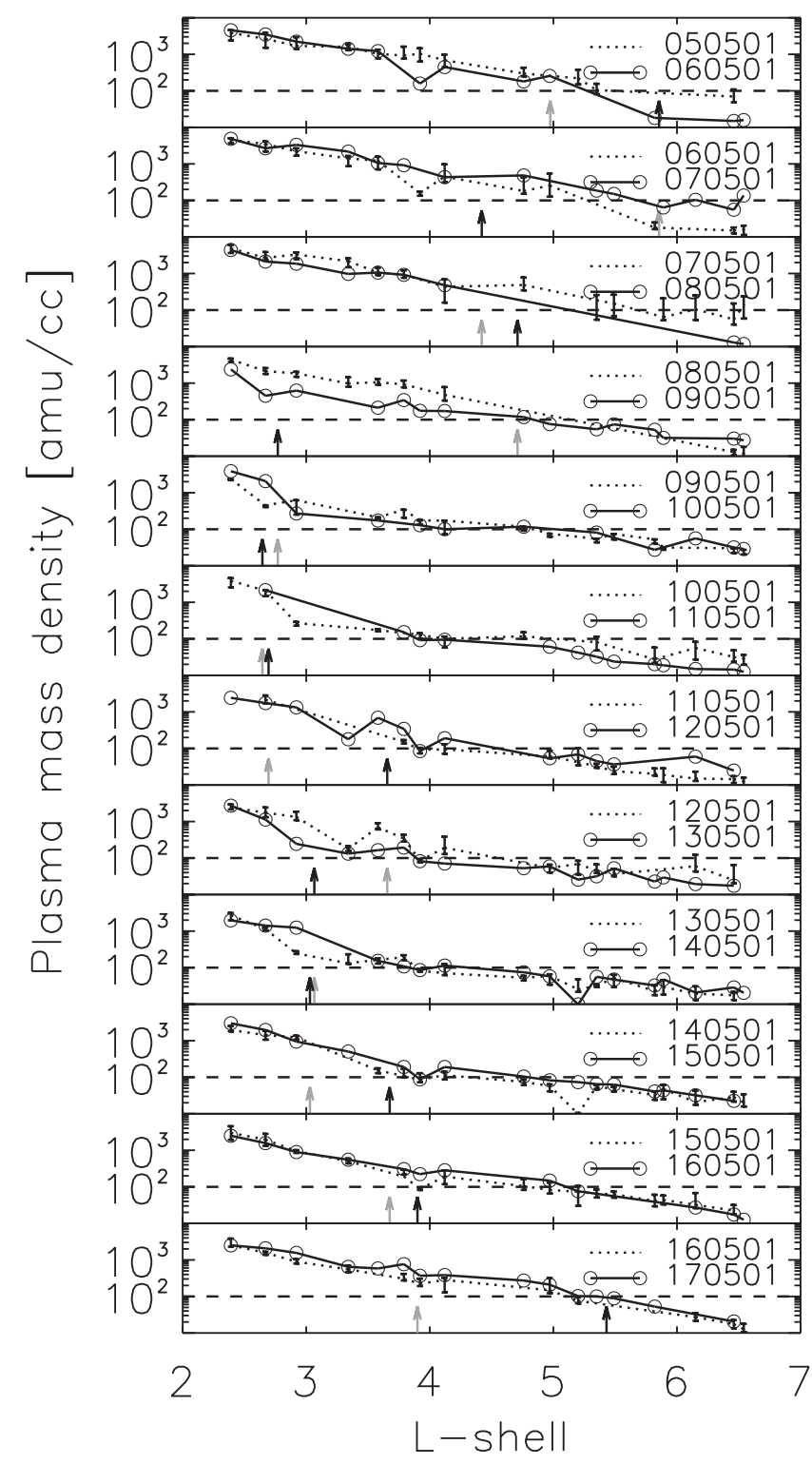

Figure 4. Stack plot showing cross-phase determined daily plasma mass density profiles for 5-17 May 2001, determined for the 0900-1000 UT interval. Note that lines are drawn connecting data points only to guide the eye. See text for details. 


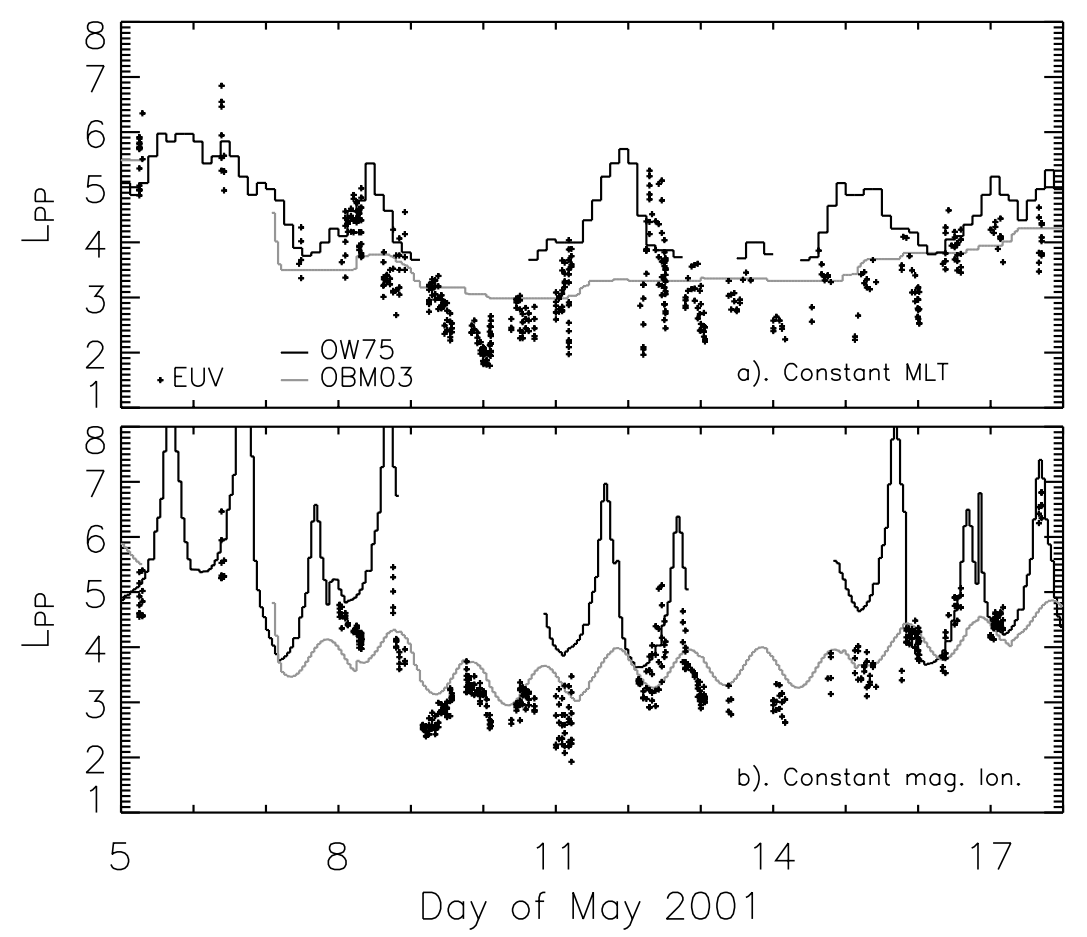

Figure 5. Observed (EUV, plus symbols) and modeled (OW75, black line; OBM03 grey line) plasmapause position, $\mathrm{L}_{\mathrm{PP}}$, as a function of UT for 5-17 May 2001: (a) For a constant magnetic local time sector, 1013-1229 MLT and (b) for a constant magnetic longitude sector, $74.87^{\circ}-108.81^{\circ}$.

pairs in this region straddling the plasmapause [e.g., Milling et al., 2001].

[22] The onset day of the second interval of enhanced geomagnetic activity was 12 May, with the solar wind parameters at ACE showing a large increase in bulk speed and dynamic pressure from $\sim 1000$ UT and the Kp and Dst indices showing increased levels of geomagnetic activity. The eigenfrequency profile (Figure 3) and corresponding plasma mass density profile (Figure 4) for this day are not monotonic between $\mathrm{L}=3.4$ and 4.1 and show the presence of a small-scale density feature in this region. The ability to again be able to perform cross-phase analysis in this region shows that the plasmapause density gradient has evolved since 11 May. This is confirmed by the EUV determined plasmapause location indicating outward motion to $\mathrm{L} \sim 3.7$ from $\mathrm{L} \sim 2.7$. The UT interval of this profile is prior to the onset of enhanced solar wind parameter values, so the plasmapause motion taking place between 11 and 12 May indicates poststorm plasma refilling taking place. Plasmaspheric erosion following this second interval of enhanced activity took place between $\mathrm{L}=2.6-3.8$ and $12-$ 13 May, being complete within $24-48$ hours of the enhancement of activity.

[23] Figure 5a shows IMAGE EUV determined plasmapause locations (plus symbols) as a function of UT for a constant MLT sector, chosen to be that spanned by the European sector ground-based magnetometers at 0930 UT. Also plotted are plasmapause locations as determined from the Orr and Webb [1975] (OW75, black line) and O'Brien and Moldwin [2003] (OBM03, grey line) empirical models. The LT dependent OW75 model is driven by the previous local nighttime average $\mathrm{Kp}$ index and was developed to determine the location of the $10 \mathrm{H}^{+} / \mathrm{cc}$ density. This model has an uncertainty of $0.4 \mathrm{~L}$ and is not valid for average $\mathrm{Kp}>$ 4. The MLT dependent OBM03 model is driven by the Dst index and was developed to determine the location of a plasmapause, as identified by a decrease of electron number density by a factor of five in less than $0.5 \mathrm{~L}$. This model is valid for $-298 \mathrm{nT} \leq$ Dst $\leq-2 \mathrm{nT}$ and has an uncertainty of $0.53 \mathrm{~L}$ for the daytime sector. The model plasmapause locations were calculated for MLT and LT corresponding to the midtime of the range covered by the European sector ground-based magnetometers 0930 UT.

[24] For comparison, Figure 5b similarly shows IMAGE EUV and empirical model predictions as a function of UT, but for a constant (i.e., corotating) magnetic longitude sector, equivalent to that spanned by the ground-based magnetometer array employed. The empirical model predictions have been plotted in order to show the statistically expected plasmapause location and to compare these predictions to observations. In particular, Figure $5 \mathrm{~b}$ shows the expected diurnal variations of plasmapause location in addition to the storm-time dynamics and hence helps to differentiate between these two effects in the EUV data. The two panels of Figure 5 show that considerable azimuthal asymmetry is present in the outer plasmasphere and that the local time history of a particular flux tube is important when studying storm-time cold plasma dynamics.

[25] The larger amount of scatter shown in Figure 5a compared to Figure $5 \mathrm{~b}$ is explained by the fact that all meridians are being monitored in Figure $5 \mathrm{a}$, and so azimuthal asymmetry due to different convection histories presents itself in the scatter. Figure $5 \mathrm{~b}$ shows a small range of scatter, which although we are following the trajectory of an assumed corotating meridian, may be explained by small-scale or mesoscale azimuthal asymmetry present in 
the longitude range being monitored or plasmasphere corotation lag $(10-15 \%$ at $\mathrm{L} \sim 3)$ [e.g., Burch et al., 2004].

[26] The diurnal cycle of outward and inward motion of the plasmapause is particularly clear in Figure $5 \mathrm{~b}$ for 9 May. Much of the motion through 9 May, including the duskside bulge, shows good agreement with the OBM03 model.

[27] Of the two models the OBM03 model shows the best overall agreement with the data through the entire study interval, as shown by its predicted values passing through the range of EUV $L_{p p}$ values. The EUV observations tend to show better agreement with the OW75 model results when the plasmapause was located at higher L-shells (i.e., during quieter intervals), and with the OBM03 model results when the plasmapause was located at lower L-shells (i.e., during more active intervals). Also, the OBM03 predicted values are mostly inward of the OW75 model predictions due to the plasmapause identification criteria of each model mentioned above. Note that these comparisons are similar to those of Webb et al. [1977], who also compared OW75 model predictions to observations. Webb et al. [1977] advised that using statistical plasmapause models to gain physical understanding should be carried out with caution.

[28] Comparing the EUV $\mathrm{L}_{\mathrm{pp}}$ locations in the two panels of Figure 5 one can gain an understanding of how the plasma depletion caused by the enhanced geomagnetic activity beginning on 7 May occurred. In Figure 5a a steady inward motion of the plasmapause is shown from 8 May until early on 10 May. The plasmapause moves steadily inward in the morning LT sector as freshly depleted flux tubes rotate into view. Note that the plasmaspheric erosion takes place over a period of 2 days. After 10 May poststorm plasma refilling takes place, as shown by an outward motion of the plasmapause. Figure $5 \mathrm{~b}$ shows some depletion through 8 May, and an inward plasmapause motion of $>1 \mathrm{R}_{\mathrm{E}}$ between late on 8 May and early on 9 May. Throughout 9 and 10 May the plasmapause undergoes a diurnal cycle while the plasmasphere remains depleted. For this meridian the depletion occurred over a period $>1$ day, followed by an additional delay of 1-2 days before refilling began.

[29] On 11 May both panels show a large range of EUV determined plasmapause location, implying either a high degree of azimuthal asymmetry associated with the onset of refilling or difficulty in determining the plasmapause location. The larger spread of plasmapause locations certainly implies that some cold plasma morphology changes had taken place since 10 May.

[30] Figure 5b shows that through 12 May the plasmapause was moving outward before moving inward later on 12 May and early on 13 May. The renewed activity began on 12 May so this plasmapause behavior is explained by continued plasma refilling followed by renewed depletion as the flux tubes passed through the nightside sector. This panel shows the plasmapause residing between $\mathrm{L} \sim 2.5$ and $\mathrm{L} \sim 4.0$ through most of 13 and 14 May, although the UT coverage is not as good as other days. The outward motion of the plasmapause from 14 until 17 May, and a large outward motion through 17 May clearly shows that refilling was taking place over this extended interval.

[31] A similarly clear picture of this secondary depletion and refilling is not present in Figure 5a, again demonstrating that the local time history of each meridian is very impor- tant, especially when the interval of enhanced geomagnetic activity was not sustained for a long period, as it was following 7 May. Importantly, plasmaspheric erosion may occur to different L-shells along different meridians, as shown by the large scatter in the $\mathrm{L}_{\mathrm{pp}}$ values throughout 13-15 May. Such a result is expected on a statistical basis from empirical models which use the local nightside geomagnetic index of the meridian of interest [e.g., Orr and Webb, 1975; Carpenter and Anderson, 1992].

[32] Figure 5 therefore shows that when studying stormtime plasmapause dynamics the local time history of a meridian is important. The time when depletion occurs and when refilling begins is not simply dependent upon the time since the convection activity began but also the local time sector which the flux tube resided in when activity began and the duration of the enhanced geomagnetic activity. This in agreement with convection theory [e.g., Nishida, 1966], i.e., azimuthal symmetry should not be assumed when monitoring storm time plasma loss and refilling.

[33] Following the activity interval beginning on 12 May the plasmasphere was not eroded to as low an L-shell as for the earlier interval which began on 7 May, consistent with the $\mathrm{Kp}$ and Dst indices showing an overall weaker level of geomagnetic activity. For the second event the plasmapause reached just beyond $\mathrm{L}=3$, shown by the positive gradient along the eigenfrequency profile on 13 May (Figure 3), and the EUV determined plasmapause location (Figures 4 and 5). Refilling at $\mathrm{L} \sim 2.9$ occurred between 13 and 14 May, and smaller amounts of refilling between $\mathrm{L} \sim 3$ and 5 continued through to 17 May.

[34] Figure 6 shows semilog plots of IMAGE RPI determined electron number density profiles for the 4-17 May 2001. Each panel shows profiles obtained at $\sim 3$ day intervals as the IMAGE satellite ground magnetic footprint was in the corresponding shaded area shown in Figure 7. Each profile was obtained in the 0850-1030 MLT sector. These results have been grouped in this way in order to examine the storm-time cold plasma dynamics along different meridians with different local time histories. In particular the time of onset of plasma loss and refilling are of interest. By examining one MLT sector, diurnal variations of plasma loss to and upflow from the ionosphere to the magnetosphere may be neglected.

[35] Following the storm onset early on 7 May two very different density profiles are obtained. Panel 2 of Figure 6 shows that $\sim 5-6$ hours after the onset of enhanced geomagnetic activity the meridian which had been in the morning sector throughout the period of enhanced activity had an extended electron number density profile with no clear plasmapause, i.e., the effects of the storm are not yet apparent along this meridian. Panel 4, however, shows that 19-20 hours after the storm onset the meridian which passed through the afternoon, evening, and nightside sectors had undergone significant depletion, as shown by the inward motion of the plasmapause from $\mathrm{L} \sim 5.5$ to $\mathrm{L} \sim$ 4.5. All other panels show that some depletion occurred between the profile preceding 7 May and that succeeding it, although the new plasmapause location and its density gradient varies from one meridian to another. For example, returning to panel 2, the profile for 10 May has a plasmapause at $\mathrm{L} \sim 2.2$, but later in the day, along the meridian 


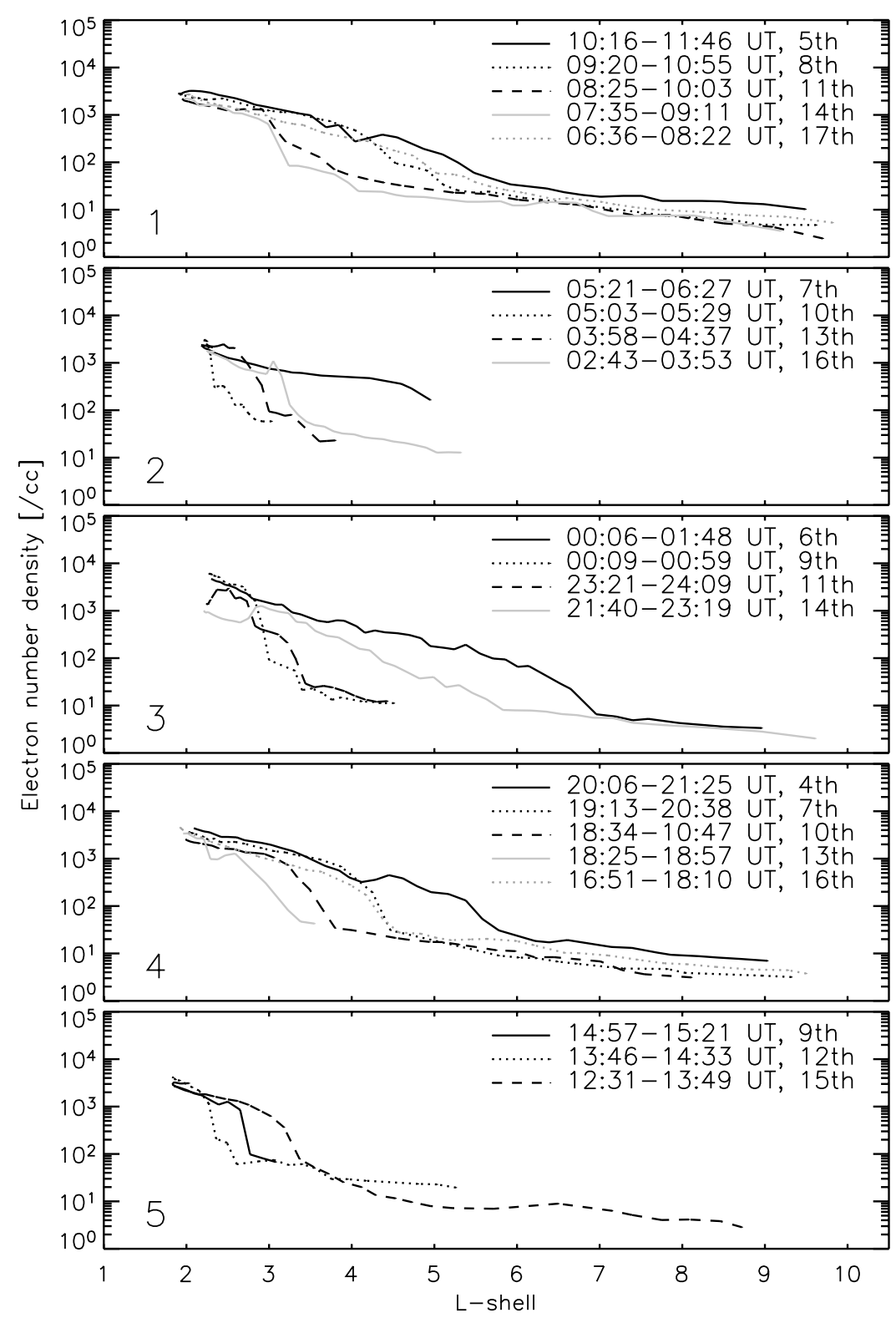

Figure 6. Stack plot of IMAGE RPI determined electron density profiles for the morning MLT sector between 4 and 17 May 2001. Each panel plots data determined when the IMAGE satellite north ground magnetic footprint was within the corresponding shaded region shown in Figure 7. Note that lines are drawn connecting data points only to guide the eye.

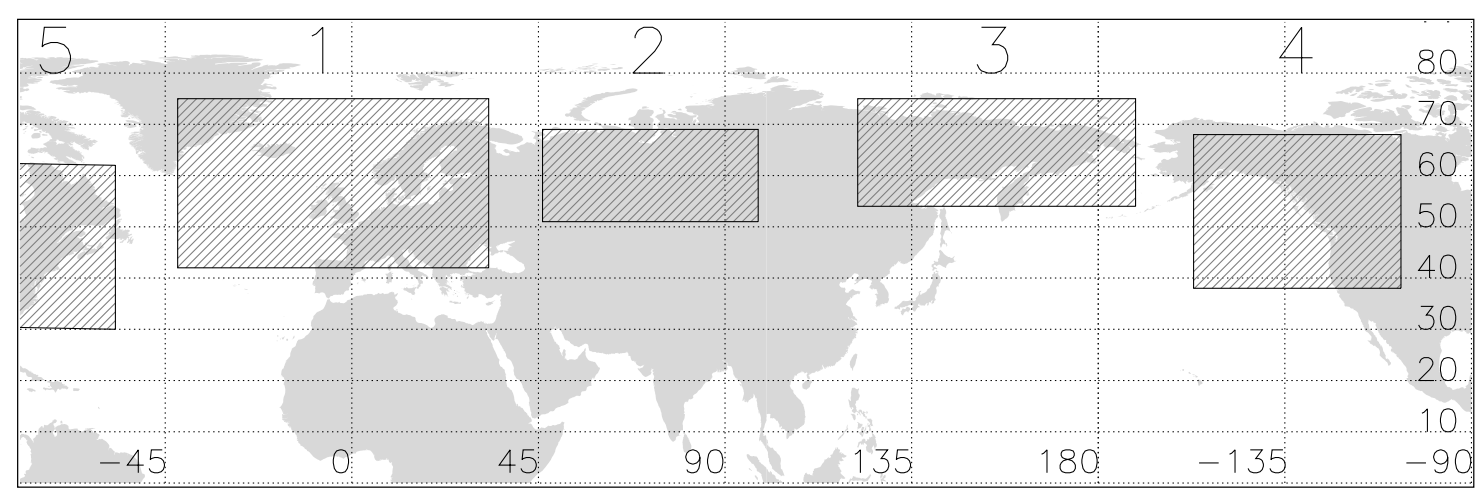

Figure 7. Map showing five areas of IMAGE satellite ground magnetic footprint corresponding to data presented in Figure 6. Satellite data was obtained as for Figure 2. 
almost $140^{\circ}$ east, panel 4 shows a plasmapause with a more gentle gradient between $\mathrm{L} \sim 3.2$ and 3.8. Note that if one follows all of the profiles presented in Figure 6 purely chronologically as the meridians rotate through the fixed local-time sector, the storm-time dynamics are not smoothly varying due to the different responses along each meridian. A similar result was also shown by Reinisch et al. [2004], who examined IMAGE RPI determined electron number density profiles in the noon sector from successive orbits throughout an interval of plasmaspheric depletion and refilling. These results highlight the effects of a time-varying convection electric field and/or shielding as the different meridians rotate through the region where plasma depletion occurs.

[36] The first four panels in Figure 6 imply that depletion took place for several days up until 11 May, the day following the peak of geomagnetic activity as shown by the Dst and Kp indices. This is shown by a gradually inward moving plasmapause through this interval in each of these panels. Following the second, shorter-lived, interval of enhanced activity on 12 May, different meridians monitored different behavior. While some meridians were eroded to inward of their pre-12 May plasmapause location, e.g., panels 1 and 4, others show no clear erosion, e.g., panels 2 and 3. At the coarse time resolution offered one cannot discount the possibility of some refilling taking place in addition to depletion, although this is unlikely given the regions, dates, and geomagnetic conditions prevalent.

[37] Regardless of whether depletion clearly occurred along any specific meridian following the 12 May activity, all panels show refilling taking place toward the end of the study interval. These profiles also show differing plasmapause profiles, some having a steep density gradient (e.g., 16 May, panel 2) and others a shallow density gradient and increased plasmatrough densities (e.g., 17 May, panel 1). This may imply that (1) the manner in which a meridian refills is dependent upon the convection activity occurring throughout refilling [e.g., Singh and Horwitz, 1992], and/or (2) refilling is an L-dependent process, taking place faster at low L-shells where flux tubes have a smaller volume [e.g., Lemaire et al., 1998].

\subsection{Conjunction Study}

[38] This extended interval of enhanced geomagnetic activity is ideal for a coordinated ground-based magnetometer and IMAGE satellite study, because the IMAGE satellite's 14.2 hour orbit produced an excellent ground magnetic footprint conjunction with ground-based magnetometer arrays in the European sector approximately every three days throughout the study interval. The Northern Hemisphere magnetic footprints of the IMAGE satellite orbit for conjunctions on 5, 8, 11, 14, and 17 May 2001 are shown in Figure 2. The times shown are those when electron number densities presented in this section were determined using IMAGE RPI instrument data. Figure 8 shows five semilog plots of plasma mass density as a function of L-shell for these conjunctions, a dashed horizontal line having been added at $100 \mathrm{amu} / \mathrm{cc}$ to aid comparison. In situ RPI derived electron number densities have been converted to plasma mass densities by assuming a solely $\mathrm{H}^{+}$ion plasma. EUV plasmapause locations are shown by arrows. Similar to Goldstein et al. [2003], these locations have been calcu- lated as the median value determined from the closest images in UT for prior and post orbits which bracket the RPI and cross-phase measurements (hence they are not coincident in UT). When the RPI and cross-phase measurements are not bracketed with EUV observations for a particular day, the EUV plasmapause location closest in UT is shown.

[39] The cross-phase determined plasma mass density profiles include mass contributions from all ion species present along the flux tube, while the RPI derived mass density has been calculated from electron density assuming a pure $\mathrm{H}^{+}$plasma. Thus any difference between the two profiles may identify either a heavy ion $\left(\mathrm{He}^{+}\right.$and/or $\left.\mathrm{O}^{+}\right)$ population or azimuthal asymmetry.

[40] By monitoring a long time interval and using repeated ground-satellite conjunctions in the same local time sector, this study hoped to avoid issues associated with intercalibration and azimuthal asymmetry effects [cf. Dent et al., 2003], thus allowing day-to-day heavy ion dynamics to be monitored. Note that only during such very close conjunctions may any inferences be confidently made about heavy ions. Any inferences of heavy ion proportions determined from comparison of the ground-based cross-phase and in situ RPI plasma mass densities will not provide any information about what specific heavy ion species are present, or their admixture. However, by monitoring several days it is possible to ascertain both whether the heavy ion population has been enhanced (depleted) and whether the hydrogen population has been depleted (enhanced).

[41] For the most part, the two mass density profiles presented in each panel of Figure 8 show small separation and often agree within the bounds of error. On 5 May, in the plasmatrough beyond $\mathrm{L}=6$ the two profiles diverge. The MLT difference between the data sets in this region was at most $\sim 3$ hours $20 \mathrm{~min}$. The day 5 May was a quiet prestorm day, in an advanced stage of refilling, as shown by the shallow density profiles. On such days irregular azimuthal density structure is commonly seen in the plasmatrough region [e.g., Goldstein et al., 2003; Dent et al., 2003]. Examining the IMAGE EUV images for 0733 UT and 1735 UT (the closest available in UT, not shown), a plume is evident in the dayside sector of the earlier image but is mostly gone by the later image. Also, the geosynchronous LANL_1994_084 satellite MPA data (not shown) shows a plume filling the dayside from $\sim 0800$ to 1800 MLT ( 0100-1100 UT). Although sampling a different sector than the conjunction study these data show the plume density being greater in the cross-phase profile MLT sector than in the IMAGE RPI MLT sector. Note that Spasojević et al. [2003] found that plumes may not corotate or may corotate at a fraction of the corotation speed. Thus from these extra data sets the difference between the cross-phase and IMAGE RPI determined plasma density values at $\mathrm{L} \sim 6.5$ may be attributed to azimuthal asymmetry owing to the MLT separation of the data sets and the existence of the dayside plume.

[42] The second region of interest with respect to heavy ions is 14 May, beyond $\mathrm{L}=4.0$ in the plasmatrough region (Figure 8). The cross-phase determined plasma mass densities are significantly greater than the RPI determined densities in this region, as compared with the other days. The cross-phase density values beyond $L=4.0$ are similar 


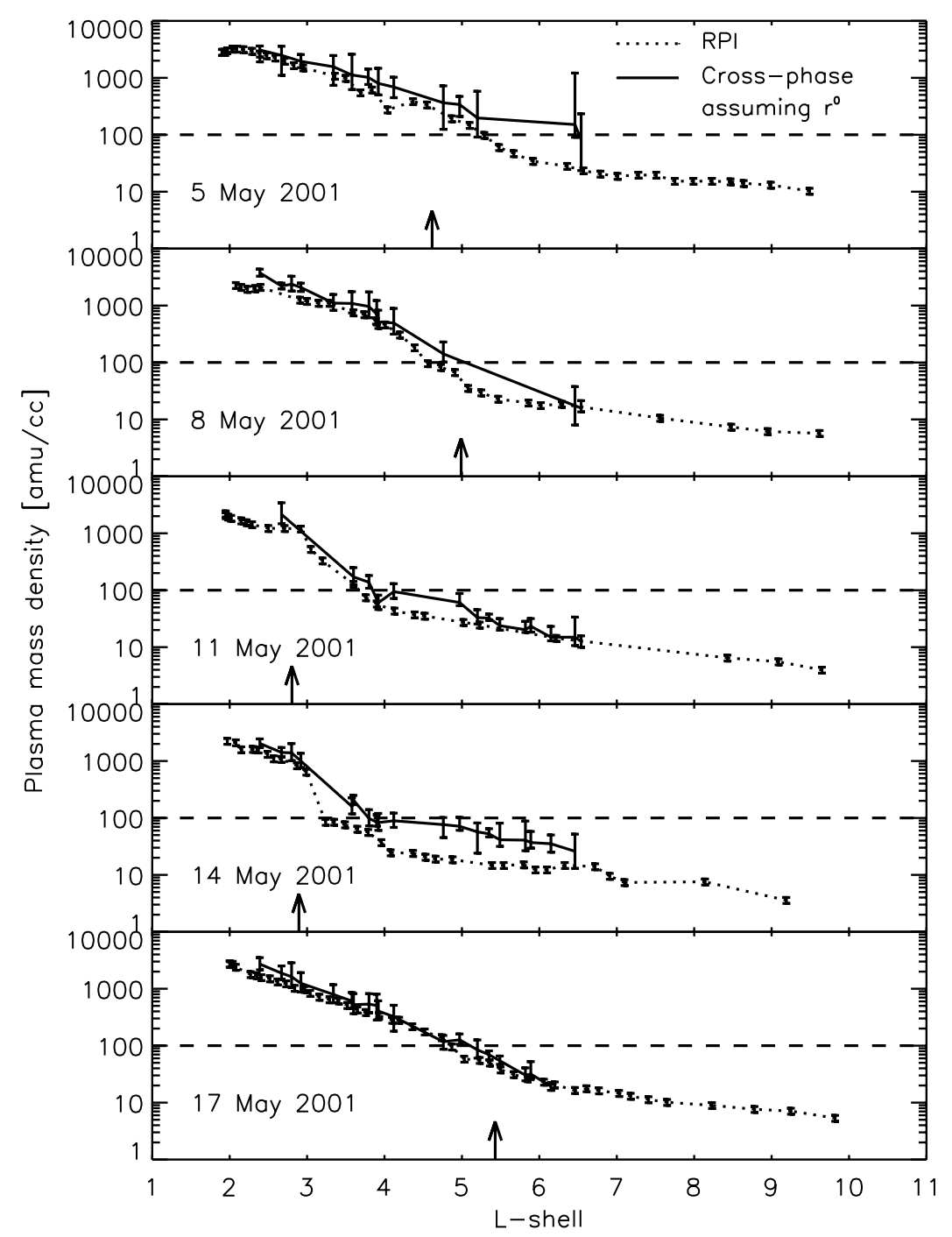

Figure 8. Cross-phase and IMAGE RPI determined plasma mass density profiles for 5, 8, 11, 14, and 17 May 2001. Arrows indicate the plasmapause location determined via IMAGE EUV analysis. Note that lines are drawn connecting data points only to guide the eye.

to or greater than those of 11 May, and the RPI determined values are generally smaller. In terms of ion interchange, this shows that the total number of ions has decreased, yet the total mass density has increased, implying an increase in the number of heavy ions present beyond $\mathrm{L}=4.0$ from 11 May to 14 May. For this conjunction the two data sets had a maximum MLT separation of 2 hours $00 \mathrm{~min}$. Examining the IMAGE EUV image for 0354 UT on 14 May (not shown) shows that the plasmapause in the magnetic longitude sector corresponding to the conjunction study (assuming appropriate corotation through the dawn sector) [e.g., Burch et al., 2004] was regularly shaped with no clearly identifiable density feature which could explain the differing results. Thus for this day the differing densities in the plasmatrough region are most likely due to an enhanced heavy ion population, rather than azimuthal asymmetry.

[43] As the admixture of the $\mathrm{H}^{+}, \mathrm{He}^{+}$, and $\mathrm{O}^{+}$ions is unknown, calculations of the density of individual specific ion species is not possible from comparisons of plasma mass and electron number density observations. Instead an "ion mass factor" may be calculated [e.g., Takahashi et al., 2004]. This is the ratio of the observed mass density to the mass density calculated from the electron density assuming a purely $\mathrm{H}^{+}$plasma. Between $\mathrm{L}=4.0$ and 5.0 this value varies between $\sim 1.8$ and 4.1 , decreasing with increasing $L$. This compares well with ion mass factor values between 2 and 6, as determined by Takahashi et al. [2004] using CRRES data for the 1200-1800 MLT sector and $4<\mathrm{L}<$ 8 throughout the CRRES mission.

[44] While our analysis cannot provide any information about the relative contributions of specific heavy ion species which may be present, our observations can be explained by the presence of an enhanced $\mathrm{O}^{+}$population in the inner plasmatrough following a depletion episode, similar to that observed by Horwitz et al. [1984] using DE-1 RIMS data. Horwitz et al. [1984] observed a torus of $\mathrm{O}^{+}$and $\mathrm{O}^{++}$ions in the inner plasmatrough during a disturbed interval and on the quiet day which followed. Horwitz et al. [1984] also found that this population initially had a field-aligned flow, 
Table 2. Cross-Phase Determined Refilling Densities

\begin{tabular}{lcccccc}
\hline Date & UT & $\begin{array}{c}\text { Density, } \\
\text { amu/cc }\end{array}$ & $\begin{array}{c}\text { Increase Since } \\
\text { Previous Day, amu/cc }\end{array}$ & UT & $\begin{array}{c}\text { Density, } \\
\text { amu/cc }\end{array}$ & $\begin{array}{c}\text { Increase Since } \\
\text { Previous Day, amu/cc }\end{array}$ \\
\hline 13 & $0920-0950$ & 70 & - & $1520-1600$ & 172 & - \\
14 & $0900-0950$ & 113 & 43 & $1705-1745$ & 172 & 0 \\
15 & $0910-0940$ & 190 & 77 & $1655-1715$ & 244 & 72 \\
16 & $0900-0930$ & 283 & 93 & $1605-1645$ & 276 & 32 \\
17 & $0920-1000$ & 383 & 100 & $1635-1715$ & 976 & 700 \\
\hline
\end{tabular}

while the $\mathrm{H}^{+}$and $\mathrm{He}^{+}$populations were essentially stationary and isotropic. Similarly, Singh and Horwitz [1992] found that during the intermediate stages of refilling the concentration of $\mathrm{O}^{+}$ions was enhanced in the almost-filled plasmasphere. Horwitz et al. [1984] also found for their study that the $\mathrm{He}^{+} / \mathrm{H}^{+}$ratio was reasonably constant with $\mathrm{L}$ in both the plasmasphere and plasmatrough regions. The inferences made about the heavy ion dynamics occurring during the study presented here are entirely consistent with a scenario of an enhanced oxygen ion torus in the plasmatrough region, outside the recently depleted plasmasphere.

[45] The source of such an enhanced $\mathrm{O}^{+}$population may be the ionosphere. Using the Millstone Hill incoherent scatter radar Yeh and Foster [1990] monitored upward $\mathrm{O}^{+}$ outflow during a large magnetic storm and state that these ions constituted a significant source of $1 \mathrm{eV} \mathrm{O}^{+}$ions to the overlying magnetosphere during such intervals.

[46] Note that on 17 May the cross-phase and RPI density profiles once again show very good agreement, suggesting that at this time very few heavy ions were present.

[47] For 17 May no clear plasmapause is apparent, but a slight increase of density gradient occurs around $\mathrm{L} \sim 4.7$, slightly inward of the EUV determined plasmapause location. Thus where a clear, steep plasmapause is present, the EUV determined plasmapause location generally agrees well with the RPI and cross-phase determined plasmapause locations. Comparing the density profiles and the EUV plasmapause locations in Figure 8 shows that the welldefined plasmapause is generally located between plasma mass densities of 1000 and $100 \mathrm{amu} / \mathrm{cc}$ and often between 500 and $100 \mathrm{amu} / \mathrm{cc}$.

[48] Note that in Figure 8, for 14 May, the RPI determined plasma mass density profile is much steeper through the plasmapause than that determined via the cross-phase analysis. For two of the cross-phase station pairs in the plasmapause region $(\mathrm{L}=3.16$ and $\mathrm{L}=3.34)$ a negative cross-phase peak was observed for part of this day (at the same UT and LT of the RPI observations). Such an observation is consistent with the plasma mass density gradient being steep enough to overcome the magnetic field (length and strength) L-shell dependence to produce a reversal in the local Alfvén frequency gradient. This will be discussed further in a separate paper.

\section{Discussion}

[49] The interval studied here contained two cold plasma depletion episodes, one following the initial increase of activity early on 7 May and the second following the increase of activity which began early on 12 May. The time taken for plasmaspheric erosion to be completed was 3-4 days following the first onset interval on 7 May and
24-48 hours following the second onset on 12 May. Although the geomagnetic indices presented in Figure 1 show further enhanced activity later on 13 May, no further plasma loss is apparent. Song et al. [1988] studied GEOS-2 geosynchronous satellite data and found that a minimum electron number density was observed 1 or 2 days after the day of minimum Dst. This time delay was attributed to limited convection velocity. The results presented in this paper show good agreement with this observation. It therefore seems that the length of time taken for depletion to be completed depends upon the length of the storm main phase and the local time-history of a particular meridian.

[50] A difficulty with studying plasma depletion is the uncertainty in determining the beginning and duration of the depletion interval, if a sector is depleted at all. During one event, Spasojević et al. [2003] found a correlation between nightside inward velocity of the plasmapause to the instantaneous strength of IMF Bz. Other studies show that the onset of depletion is expected to occur in the local dusk region, however [e.g., Kersley and Klobuchar, 1980; Degenhardt et al., 1977]. These results are not mutually exclusive. Duskside loss may be associated with convection to the magnetopause, whereas nightside plasmapause motion may indicate loss to the ionosphere [e.g., Carpenter and Lemaire, 1997].

[51] Our results show that there is a local time asymmetry involved in the depletion process such that all sectors monitored were not depleted simultaneously or to the same L-shell. Spasojević et al. [2003] reported the presence of crenulations, bulges, and shoulders in the dayside sector during geomagnetically disturbed intervals. Thus azimuthal variation of plasmapause location could be formed in response to the time-varying IMF Bz (and thus time-varying convection electric field) as each meridian passed through the nightside sector. A nonuniform convection electric field or shielding may also cause azimuthally asymmetric plasmapause erosion.

[52] The depletion, calculated as a percentage of the prestorm plasma remaining, has been determined for $\mathrm{L}=$ 2.92 and $\mathrm{L}=4.12$ for each plasma erosion event. At $\mathrm{L}=$ 4.12 the value calculated for the first and second intervals were $22 \%$ and $37 \%$, while at $\mathrm{L}=2.92$ depletion was $7 \%$ and $18 \%$, respectively. This suggests a dependence on both L and the time taken for depletion to complete. These values may be compared to those of Reinisch et al. [2004] and Degenhardt et al. [1977]. Reinisch et al. [2004] used IMAGE RPI data to determine a depletion value of $<33 \%$ at $\mathrm{L}=2.84$, and Degenhardt et al. [1977] used TEC values in the plasmasphere up to geosynchronous orbit to determine a depletion value of $50 \%$. Note that our values were calculated using data from Figure 4, so at this resolution the maximum prestorm or minimum poststorm values may not 
have been represented in the calculation. This may result in an overestimation or underestimation of the depletion value.

[53] Figures 4 and 8 show that plasma refilling took place between $\mathrm{L} \sim 3.8$ and 5.2 and 14-17 May 2001. Daily refilled densities have been determined for $\mathrm{L}=4.12$ (HANOUL) using the results presented in Figure 4 and from the maximum observed density each day (note that the plasma mass density may have increased further beyond the limit of the cross-phase observations each day). These values are shown in Table 2 and may be considered to be daily refilling rates. Any corotation lag occurring would mean that exactly the same flux tube is not monitored from day to day. Using ground-based instruments this cannot be avoided, however.

[54] These refilling values show that the local time when refilling is calculated is a very important factor. While the local morning sector results show the amount refilled each day increasing with time, the daily maximum values from the afternoon sector show varying amounts of plasma density increase for the first 3 days and a very large increase on the fourth day. The afternoon values represent the state of the flux tube after one extra day of refilling than the morning values for the same day, but regardless of this different refilling trends are shown in the two local time sectors. Note also that the daily maximum values show no refilling between 13 and 14 May. This may be explained by plasma drainage in the afternoon sector of 14 May or heavy ion interchange with the underlying ionosphere.

[55] These results suggest that the nightside loss of plasma to the ionosphere is an important factor in moderating the rate of refilling. Note also that no net refilling took place throughout 16 May so daytime refilling must depend upon other factors than simply the lack of plasma along the flux tube.

[56] Song et al. [1988] suggested that the prevailing Dst will moderate the refilling rate and developed an empirical model based on GEOS-2 data for determining refilling rate at geosynchronous orbit in duskside bulge region. Assuming that the refilling rate from the ionosphere is constant per unit area across dipolar L-shells, then the refilling rate, $\mathrm{d} \rho /$ $\mathrm{dt}$, will scale $\sim \mathrm{L}^{-4}$ under the approximation that $1 / \mathrm{L} \ll 1$. Using their formula and scaling according to $\mathrm{L}^{-4}$ gives a value at $\mathrm{L}=4.12$ of 95 electrons $/ \mathrm{cm}^{3} /$ day throughout the refilling interval observed. This result has better agreement with our morning-side results than our afternoon sector ones.

[57] The refilling rates monitored in the afternoon sector by the HAN-OUL station pair may also provide some evidence in support of a two-stage refilling process. Lawrence et al. [1999] and Su et al. [2001] statistically studied data from the Magnetospheric Plasma Analyzers on board several Los Alamos geosynchronous satellites and found evidence for a two-stage refilling process, the rate of refilling during the first 24 hours ("early-time refilling") being slower than the following days ("late-time refilling"). These studies showed early-time refilling rates at geosynchronous orbit of 0.6-12 ions $\mathrm{cm}^{-3}$ day $^{-1}$ and late-time refilling rates of 10-25 ions $\mathrm{cm}^{-3}$ day $^{-1}$. Using the above dipolar flux tube cross-section method to compare these geosynchronous results to those at $\mathrm{L}=4.12$ gives an early-time refilling rate of $4-80$ ions $\mathrm{cm}^{-3}$ day $^{-1}$ and a late-time refilling rate of $67-166$ ions $\mathrm{cm}^{-3}$ day $^{-1}$. These results compare well with our morning sector results but not so well with the afternoon sector ones. Note that if the heavy ion population decreased throughout the refilling interval, as implied by the data presented in Figure 8 for 14 and 17 May, then the rate in terms of ions $\mathrm{cm}^{-3}$ day $^{-1}$ determined using observed plasma mass densities will be artificially low.

[58] Note that $\mathrm{Su}$ et al. [2001] began their refilling rate calculation when the $\mathrm{Kp}$ index fell to $1+$ or lower and continued as long as this condition was met. This condition was not met through our refilling interval, however, although it is clear that such a low $\mathrm{Kp}$ value is not required before refilling is observed at $\mathrm{L}=4.12$.

[59] To explain this two-stage refilling process, Lawrence et al. [1999] suggested a scenario modeled by Wilson et al. [1992] where Coulomb collisions may be the dominant trapping mechanism, and once some critical density is reached then the refilling rate will increase. Wilson et al.'s [1992] model showed the change from early- to late-time refilling occurred at some specific density and that this transition was also accompanied by a change from fieldaligned to isotropic ion distributions.

[60] This two-stage refilling scenario is not supported by other authors, however. Park [1970], for example, monitored refilling of electrons in the midnight sector and at Lshells between 3.5 and 5.0 using ground-based whistler observations. He observed the whistler duct plasma content to increase at a nearly constant rate during 5 extremely quiet days, after which the refilling rate decreased. Note that our results have shown that local time is an important factor when monitoring poststorm refilling, and Singh and Horwitz [1992] note that the initial plasma content in a flux tube is an important factor for subsequent refilling. These factors may explain this disagreement.

[61] Along the RPI determined plasma mass density profile for 14 May 2001, shown in Figure 8, a small-scale density depletion occurs between $\mathrm{L}=2.27$ and 2.57 . This is not apparent along the cross-phase determined profile but may be explained by the spacing of the ground-based magnetometer pair, which spans $\mathrm{L}=2.25-2.56$. Menk et al. [2004] discussed in detail the ability to detect localized magnetospheric density structures using the cross-phase and related techniques. Such small-scale plasmaspheric depletions are not uncommon and Lemaire et al. [1998] note that such depletions and their subsequent recovery have been observed since the early 1960s. Clilverd et al. [2000] studied 10 years worth of VLF data and found that depletion events occurred within 3 days of the Kp index reaching 5 or more were centered about $\mathrm{L}=2.4$, and the majority of these depletions occurred within the plasmasphere, in excellent agreement with the RPI observations shown in Figure 8. Using measurements made on board the ISEE satellite [Carpenter and Lemaire, 1997] also observed regions of electron density depletion in the inner plasmasphere following geomagnetic disturbances. Possible scenarios to explain these depletions include outward moving flux tubes [e.g., Smith and Clilverd, 1991] and loss to the ionosphere [e.g., Carpenter and Lemaire, 1997].

\section{Conclusions}

[62] In this paper we have presented ground-based magnetometer cross-phase and IMAGE satellite in situ RPI 
monitoring of plasma depletion and refilling throughout a prolonged interval of moderate geomagnetic activity between 5 and 17 May 2001. During this interval a series of excellent ground-satellite conjunctions also occurred, enabling heavy ion dynamics to be inferred. In addition, IMAGE EUV and empirical model determined plasmapause locations were analyzed for the same interval.

[63] Plasmaspheric erosion to $\mathrm{L}<3$ was monitored following the onset of a geomagnetic storm on 7 May, and again to a higher L-shell during an interval of renewed activity which occurred during the recovery phase on 12 May. Plasma loss took place for more than 3 days following the first depletion episode and plasma refilling was clearly observed for several days following the second depletion interval. Refilling rates determined from the crossphase results for $\mathrm{L}=4.12$ for the morning sector and using the daily maximum observed plasma mass density showed different trends, implying that refilling along an assumed corotating flux tube does not proceed at a uniform rate through the dayside sector, or from day to day.

[64] Good agreement was found between the cross-phase and IMAGE EUV and RPI observations, particularly with respect to the dynamic motion of the plasmapause. Empirical plasmapause models showed reasonable agreement with the EUV determined plasmapause locations, the $\mathrm{Orr}$ and Webb [1975] (OW75) model showing better agreement during quieter times and the O'Brien and Moldwin [2003] (OBM03) model showing better agreement during more active times. The OBM03 plasmapause estimates were consistently at lower L-shells than those of the OW75 model, and this is due to the differing plasmapause identification criteria for the two models.

[65] The cross-phase and IMAGE RPI conjunction study showed that the presence of heavy ions may be inferred when ground-based magnetometer and in situ satellite determined mass density profiles diverge, but one must first discount the presence of azimuthal density asymmetry as the cause of the difference between the two density profiles.

[66] This study demonstrates and further illuminates the utility of multiinstrument studies for monitoring the dynamics of the plasma populations in the inner magnetosphere including plasmaspheric motion and heavy ion injection. In future, using ground-based magnetometers along more than one meridian would add insight into the issue of the effect of local time history on plasma depletion and global plasmaspheric morphology.

[67] Acknowledgments. The IMAGE magnetometer data are collected as a Finnish-German-Norwegian-Polish-Russian-Swedish project and we thank those institutes which maintain the array. The IMAGE magnetometer data was provided by the Finnish Meteorological Institute. BGS is a NERC funded facility, and SAMNET is a PPARC National Facility currently operated by Lancaster University (formerly by the University of York). We thank the SAMNET team for providing the SAMNET and BGS magnetometer data. The authors thank B. W. Reinisch and B. R. Sandel for IMAGE RPI and EUV data, respectively. We acknowledge N. F. Ness for the ACE MAG data, D. J. McComas for ACE SWEPAM data, M. Thomsen for LANL MPA data, the World Data Center for Geomagnetism, Kyoto for Dst and Kp indices, and NSSDCWeb for MLT calculations. R. E. McGuire at SSC Web is acknowledged for the IMAGE satellite orbit data. ZCD was funded by a PPARC studentship during part of this study. IRM is supported by a Canadian NSERC Discovery Grant. JG wishes to acknowledge support through NASA Sun-Earth Connections Guest Investigator program grant NAG5-12787, and NASA IMAGE Mission grant NAS5-96020. FWM is supported by the Australian Research Council, the University of
Newcastle, and the Cooperative Research Centre for Satellite Systems through the Commonwealth of Australia CRC program.

[68] Arthur Richmond thanks David Berube and another reviewer for their assistance in evaluating this paper.

\section{References}

Angerami, J. J., and D. L. Carpenter (1966), Whistler studies of the plasmapause in the magnetosphere: 2 . Electron density and total tube content near the knee in magnetospheric ionization, J. Geophys. Res., 71(3), $711-725$.

Baransky, L. N., S. P. Belokris, Y. E. Borovkov, M. B. Gokhberg, E. N. Federov, and C. A. Green (1989), Restoration of the meridional structure of geomagnetic pulsation fields from gradient measurements, Planet. Space Sci., 37(7), 859-864.

Bezrukikh, V. V., M. I. Verigin, G. A. Kotova, L. A. Lezhen, Y. I. Venediktov, and J. Lemaire (2001), Dynamics of the plasmasphere and plasmapause under the action of geomagnetic storms, J. Atmos. Sol. Terr. Phys., 63, $1179-1184$

Burch, J. L., J. Goldstein, and B. R. Sandel (2004), Cause of plasmasphere corotation lag, Geophys. Res. Lett., 31, L05802, doi:10.1029/ 2003GL019164.

Carpenter, D. L., and R. R. Anderson (1992), An ISEE/whistler model of equatorial electron density in the magnetosphere, J. Geophys. Res., 97(A2), 1097-1108

Carpenter, D. L., and J. Lemaire (1997), Erosion and recovery of the plasmasphere in the plasmapause region, Space Sci. Rev., 80, 153-179.

Carpenter, D. L., and C. G. Park (1973), On what ionospheric workers should know about the plasmapause-plasmasphere, Rev. Geophys., 11(1), 133-154

Chappell, C. R., K. K. Harris, and G. W. Sharp (1971), The dayside of the plasmasphere, J. Geophys. Res., 76(31), 7632-7647.

Clilverd, M. A., B. Jenkins, and N. R. Thomson (2000), Plasmaspheric storm time erosion, J. Geophys. Res., 105(A6), 12,997-13,008.

Craven, P. D., D. L. Gallagher, and R. H. Comfort (1997), Relative concentration of $\mathrm{He}^{+}$in the inner magnetosphere as observed by the DE 1 retarding ion mass spectrometer, J. Geophys. Res., 102(A2), 2279-2289.

Degenhardt, W., G. K. Hartmann, and R. Leitinger (1977), Effects of a magnetic storm on the plasmasphere electron content, Planet. Space Sci., 39, 1435-1440.

Dent, Z. C., I. R. Mann, F. W. Menk, J. Goldstein, C. R. Wilford, M. A. Clilverd, and L. G. Ozeke (2003), A coordinated ground-based and IMAGE satellite study of quiet-time plasmaspheric density profiles, Geophys. Res. Lett., 30(12), 1600, doi:10.1029/2003GL016946.

Denton, R. E., J. D. Menietti, J. Goldstein, S. L. Young, and R. R. Anderson (2004), Electron density in the magnetosphere, J. Geophys. Res., 109, A09215, doi:10.1029/2003JA010245.

Fraser, B. J., J. L. Horwitz, J. A. Slavin, Z. C. Dent, and I. R. Mann (2005), Heavy ion mass loading of the geomagnetic field near the plasmapause and ULF wave implications, Geophys. Res. Lett., 32, L04102, doi:10.1029/2004GL021315

Gallagher, D. L., P. D. Craven, and R. H. Comfort (2000), Global core plasma model, J. Geophys. Res., 105(A8), 18,819-18,833.

Goldstein, J., R. E. Denton, M. K. Hudson, E. G. Miftakhova, S. L. Young, J. D. Menietti, and D. L. Gallagher (2001), Latitudinal density dependence of magnetic field lines inferred from Polar plasma wave data, J. Geophys. Res., 106(A4), 6195-6201.

Goldstein, J., M. Spasojević, P. H. Reiff, B. R. Sandel, T. Forrester, D. L. Gallagher, and B. W. Reinisch (2003), Identifying the plasmapause in IMAGE EUV data using IMAGE RPI in situ steep density gradients, J. Geophys. Res., 108(A4), 1147, doi:10.1029/2002JA009475.

Goldstein, J., B. R. Sandel, M. F. Thomsen, M. Spasojević, and P. H. Reiff (2004), Simultaneous remote sensing and in situ observations of plasmaspheric drainage plumes, J. Geophys. Res., 109, A03202, doi:10.1029/ 2003JA010281

Horwitz, J. L., R. H. Comfort, and C. R. Chappell (1984), Thermal ion composition measurements of the formation of the new outer plasmasphere and double plasmapause during storm recovery phase, Geophys. Res. Lett., 11(8), 701-704.

Kersley, L., and J. A. Klobuchar (1980), Storm associated protonospheric depletion and recovery, Planet. Space Sci., 28, 453-458.

Lawrence, D. J., M. F. Thomsen, J. E. Borovsky, and D. J. McComas (1999), Measurements of early and late time plasmasphere refilling as observed from geosynchronous orbit, J. Geophys. Res., 104(A7), $14,691-14,704$

Lemaire, J. F., K. I. Gringauz, D. L. Carpenter, and V. Bassolo (1998), The Earth's Plasmasphere, Cambridge Univ. Press, New York.

Lühr, H., A. Aylward, S. C. Buchert, A. Pajunpää, K. Pajunpää, T. Holmboe, and S. M. Zalewski (1998), Westward moving dynamic substorm features observed with the IMAGE magnetometer network and other ground-based instruments, Ann. Geophys., 16, 425-440. 
Menk, F. W., D. Orr, M. A. Clilverd, A. J. Smith, C. L. Waters, D. K. Milling, and B. J. Fraser (1999), Monitoring spatial and temporal variations in the dayside plasmasphere using geomagnetic field line resonances, J. Geophys. Res., 104(A9), 19,955-19,969.

Menk, F. W., I. R. Mann, A. J. Smith, C. L. Waters, M. A. Clilverd, and D. K. Milling (2004), Monitoring the plasmapause using geomagnetic field line resonances, J. Geophys. Res., 109, A04216, doi:10.1029/ 2003JA010097.

Milling, D. K., I. R. Mann, and F. W. Menk (2001), Diagnosing the plasmapause with a network of closely spaced ground-based magnetometers, Geophys. Res. Lett., 28(1), 115-118.

Nishida, N. (1966), Formation of plasmapause, or magnetospheric plasma knee, by the combined action of magnetospheric convection and plasma escape from the tail, J. Geophys. Res., 71(23), 5669-5679.

O'Brien, T. P., and M. B. Moldwin (2003), Empirical plasmapause models from magnetic indices, Geophys. Res. Lett., 30(4), 1152, doi:10.1029/ 2002 GL016007.

Orr, D., and H. W. Hanson (1981), Geomagnetic pulsation phase patterns over an extended latitudinal arrray, J. Atmos. Terr. Phys., 43(9), 889 910 .

Orr, D., and J. A. D. Matthew (1971), The variation of geomagnetic micropulsation periods with latitude and the plasmapause, Planet. Space Sci., 19, 897-905.

Orr, D., and D. C. Webb (1975), Statistical studies of geomagnetic pulsations with periods between 10 and $70 \mathrm{sec}$ and their relationship to the plasmapause region, Planet. Space Sci., 23, 1169-1178.

Ozeke, L. G., and I. R. Mann (2005), High and low ionospheric conductivity standing guided Alfvén wave eigenfrequencies: A model for plasma density mapping, J. Geophys. Res., 110, A04215, doi:10.1029/ 2004JA010719.

Park, C. G. (1970), Whistler observations of the interchange of ionization between the ionosphere and protonosphere, J. Geophys. Res., 75(22), $4249-4260$

Radoski, H. R. (1967), A note on oscillating field lines, J. Geophys. Res., $72(1), 418-419$.

Reinisch, B. W., et al. (2000), The Radio Plasma Imager investigation on the IMAGE spacecraft, Space Sci. Rev., 91, 319-359.

Reinisch, B. W., X. Huang, P. Song, G. S. Sales, S. F. Fung, J. L. Green, D. L. Gallagher, and V. M. Vasyliunas (2001), Plasma density distribution along the magnetospheric field: RPI observations from IMAGE, Geophys. Res. Lett., 28(24), 4521-4524.

Reinisch, B. W., X. Huang, P. Song, J. L. Green, S. F. Fung, V. M. Vasyliunas, D. L. Gallagher, and B. R. Sandel (2004), Plasmaspheric loss and refilling as a result of a magnetic storm, J. Geophys. Res., 109, A01202, doi:10.1029/2003JA009948.

Sandel, B. R., et al. (2000), The extreme ultraviolet imager investigation for the IMAGE mission, Space Sci. Rev., 91(1-2), 197-242.
Singh, N., and J. L. Horwitz (1992), Plasmasphere refilling: Recent observations and modeling, J. Geophys. Res., 97(A2), 1049-1079.

Smith, A. J., and M. A. Clilverd (1991), Magnetic storm effects on the midlatitude plasmasphere, Planet. Space Sci., 39(7), 1069-1079.

Song, X.-T., R. Gendrin, and G. Caudal (1988), Refilling process in the plasmasphere and its relation to magnetic activity, J. Atmos. Terr. Phys., $50(3), 185-195$.

Spasojević, M., J. Goldstein, D. L. Carpenter, U. S. Inan, B. R. Sandel, M. B. Moldwin, and B. W. Reinisch (2003), Global response of the plasmasphere to a geomagnetic disturbance, J. Geophys. Res., 108(A9), 1340, doi:10.1029/2003JA009987.

Su, Y.-J., M. F. Thomsen, J. E. Borovsky, and D. J. Lawrence (2001), A comprehensive survey of plasmasphere refilling at geosynchronous orbit, J. Geophys. Res., 106(A11), 25,615-25,629.

Takahashi, K., R. E. Denton, R. R. Anderson, and W. J. Hughes (2004), Frequencies of standing Alfvén wave harmonics and their implication for plasma mass distribution along geomagnetic field lines: Statistical analysis of CRRES data, J. Geophys. Res., 109, A08202, doi:10.1029/ 2003JA010345.

Taylor, H. A., Jr., H. S. Brinton, and C. R. Smith (1965), Positive ion composition in the magnetoionosphere obtained from the Ogo-A satellite, J. Geophys. Res., 70(23), 5769-5781.

Waters, C. L., F. W. Menk, and B. J. Fraser (1991), The resonance structure of low latitude Pc3 geomagnetic pulsations, Geophys. Res. Lett., 18(12), $2293-2296$

Webb, D. C., L. J. Lanzerotti, and C. G. Park (1977), A comparison of ULF and VLF measurements of magnetospheric cold plasma densities, J. Geophys. Res., 82(32), 5063-5072.

Wilson, G. R., J. L. Horwitz, and J. Lin (1992), A semikinetic model for early stage plasmasphere refilling: 1 . Effects of Coulomb collisions, J. Geophys. Res., 97(A2), 1109-1119.

Yeh, H.-C., and J. C. Foster (1990), Storm time heavy ion outflow at midlatitude, J. Geophys. Res., 95(A6), 7881-7891.

Yeoman, T. K., D. K. Milling, and D. Orr (1990), Pi2 pulsation polarization patterns on the U.K. sub-auroral magnetometer network (SAMNET), Planet. Space Sci., 38(5), 589-602.

Z. C. Dent, I. R. Mann, and L. G. Ozeke, Department of Physics, University of Alberta, Edmonton, AB, Canada, T6G 2J1. (zdent@phys. ualberta.ca; imann@space.ualberta.ca; lozeke@phys.ualberta.ca)

J. Goldstein, Space Science and Engineering Division, Southwest Research Institute, 6220 Culebra Road, San Antonio, TX 78238, USA (jgoldstein@swri.edu)

F. W. Menk, School of Mathematical and Physical Sciences and CRC for Satellite Systems, University of Newcastle, Callaghan, NSW 2308, Australia. (fred.menk@newcastle.edu.au) 